Die specifische Anwendung des Heilser'uus kanu sich nur auf echte Diphtherie beziehen. Die bacteriologische Diagnose jedoch nimmt 24 , manchmal 36 Stunden in Anspruch. In progredienten Fällen kann das lange Warten von Gefahr sein, und eben ans diesem Grunde wird in den meisten Spitälern - gestiïtzt anf die klinische Diagnose - das Serunı sofort angewendet. Es ist zweifellos, dass die Serumbehandlung hei der Psendodiphtherie nutzlos ist, und diese Fälle bilden eine nicht geringe Zahl der Diphtheritisfalle. Wir milssen aber bei der relativen Unschuldigkeit des Antitoxins die sofort angewandte Injection (bevor wir die Diagnose auf bacteriologischem Wege bestätigt haben) ans praktischen Gründen für gerechtfertigt halten. Die unangenehmen Nebenerscheinungen, die bis jetzt bei der' Ser'mmbehandlung beobachtet worden sind, sind nach Kossel dem Serım der Thierspecies (Pferd) zuzuschreiben, wogegen diese bei Kunserum ausbleiben. Es ist möglich, dass nur das ïberfliussige und nicht verbranchte Antitoxin diese unangenehmen Erscheinungen verursacht, $11 \mathrm{~m}$ so eher, da die beziiglichen Beschwerden sich meist auf Immunisirte und Erwachsene beziehen, d. h. wo die Toxinproduction eine geringe ist oder im Organismus das iiberfliissige Antitoxin leichter zurückbleibt.

Wie oben erwälnt, erfolgt die erste Injection in den meisten

\section{Ein mit Serum behandelter Fall von Streptococcendiphtherie.}

\section{Von Dr. Koloman Szegö in Budapest.}

Naclı Roux und Belıring ist die antidiphtheritisclıe Serumbelıandlung nur in Fällen echter Diphtherie d. h. wo das ätiologische Moment der L o effler'sche Bacillns bildet, indicirt. Die iibrigen Rachenerkrankungen, dic durch Staphylococcen, Strepto- oder Pneumococcen verursacht werden - mögen die klinischen Erscheinungen noch so ernst, fiir Diphtherie noch so charakteristisch sein - , sind fïr die antidiphtheritische Serumbehandlıng nicht geeignet. Es ist daher die bacteriologische Untersuchung bei der Beurtheilung des Werthes der Serumbehandlung von nicht geringer Bedentung. Aber auch in prognostischer Beziehung besitzt sic eine grosse Wichtigkeit, da die begleitenden Mikroben der Lo effle rscheı Bacillen im gewissen Grade die Intensität der Erkrankung zeigen. Ans diesem Grunde ist die Classificirung der französischen Schule gerechtfertigt; sie unterscheidet - seit der Serumbehandlung — zwei Klassen von Diphtherie, und zwar eine, wo nur L o effler'sche Bacillen gefunden werden: ,reine Diphtherie“, und eine, wo neben den Loeffler'schen Bacillen auch andere gefunden werden: gemischte Diphtherie". In der letzten Gruppe steht der durch kleine Coccen oder Staphylococcen verurrsachten guttartigen Gruppe die Streptococceninfection gegenüber, welche die septische Infection in sich birgt. Sie ist die gefährlichste Connplication der Dinhtherie: sie trïgt vicl dazı bei, die schönen Erfolge der Serumbehandlıng illusorisch zll machell. Die bezüglich des Einflısses der Streptococcen unternommenen Untersuchingen sind gering an Zahl. Experimentell befassten sich mit der Frage Roux und Yersin, Schreiber, Barbier und haben durch Thierexperimente bewiesen, dass die Injection einer nicht tödtlichen Dose Diphtheritisgiftes neben gleichzeitiger Injection von Streptococcenculturen todtlich geworden ist. In der letzten Zeit hat F u n c k (Zeitschrift für Hygiene und Infectionskrkh., 1894, XVII, 3 ) ïhnliche Untersuchungen unternommen und constatirt, dass mit Diphtherieheilserum präparirte Thiere die nachträgliche Diphtherievergiftung, trotz der gleichzeitig stattgefundenen Streptococceninjection, überstanden haben, und zwar sowohl die mit Toxin als die mit Mikroben verursachte Infection. Auch hat er beweisen können die gesteigerte Diphtheriegiftproduction bei gleichzeitiger Anwesenheit der Streptococcen. Die Experimente bedürfen vieler Umsicht, da die Virulenz der Streptococcen sehr schwankend ist

Die günstigen Erfolge der Serumbehandlung scheinen heutzutage zweifellos zu sein. Die Anhänger der Serumbehandlung bilden die tiberwiegonde Zahl, sie nimmt von Tag zu Tag zll. Hierher gehören die Beobachter grösseren Materials, die Leiter der Kinderhospitäler, Kliniken, die in erster Reihe Gelegenheit hatten, sich von dem Werth der Serumbehandlung zu iiberzengen und die erzielten Erfolge mit denen anderer Jahre zu veroleichen. Jedernianu, der einen geeigneten Fall beobachtet hat, konnte es wahrnehmen, dass das Serum ein specifisches Mittel ist dass der Krankheitsprocess cinen nngewöhnlichen Verlanf ninmt, wie wir iln friiher, bei anderer Bchandlung, nicht beobachtet haben. Jeder, der ilber ein grösseres Material verfiigte, sah gewiss einen oder zwei sehr schwere Fälle, die unerwartet einen gillnstigen Verlauf nalımen und sich allmählich besserten. Aber eine rapide Wendung wurde bei der alten Behandlıngsmethode kaum beobachtet. Die Bessernng des Alloemeinbefindens in 24-48 Stunden nach der Injection, die rasche Aenderung des Lokalprocesses sind Vortheile, die wir der Serumbehandlung zilschreiben können.

Und wenn diese, von einem specifischen Mittel geforderte Eigenschaft ulıs anch manchmal im Stich lässt, so ist die Ursache entweder in den begleitenden Bacterien, hauptsächlich den Streptococcen, oder in den schon friihzeitig eingetretenen degenerativen Vorgängen zll suchen. Dass diese Degenerationen schon frïhzeitig auftreten können, beweist z. B. der Fall Meyer's, der an der Leiche nach dreitägiger Krankheit in den peripheren Nervenfasern anatomische Veränderıngen gefunden hat. Dic bei der Serımbehandlıng eintretenden Herzlähmungen, Nierenalterationen oder Nervenlähmungen können auf dieser Basis leicht erklärt werden. Nachtheilig ist der Mangel unserer pharmakognostischen Kenntnisse über das Serım und demzufolge die lungenügende Dosirung desselben. Wir wollen hoffen, dass diese unbedentenden Nachtheile schon in Bälde beseitigt sein werden.

1) Sitzıng der Brit. med. Assoc. 30. Juli bis 2. Angust 1895. Semaine inédicale 1895,7 . August.
Spitälern, bevor eine bacteriologische Untersuchung stattgefunden hat, die weitere Behandlıng wird von dem bacteriologischen Befind abhängig gemacht. In der Privatpraxis nnd hauptsächlich in der Provinz ist die bacteriologische Untersıchung schwer durchzıführen, und denızıfolge kann es leicht vorkonmen, dass das Serum in unrichtigen Fällen angewendet wird. Ueber einen solchen Fall will ich berichten. Ich habe trotz wiederholtor Untersuchungen keine Loeffler'schen Bacillen gefunden, die Colonieen bestanden hauptsächlich alls Streptococcen nnd einigen Staphylococcen. Es ist nicht wahrscheinlich, dass mein Fall mit dem von Kossel identisch ist, der trotz fleissiger Untersuchung erst später im Ohreneiter L oeffler'sche Bacillen fand. Ich kann anch nicht daran denken, dass die Streptococencolonieen dic diphtheritischen iberwuchert haben. Es ist wahrscheinlich, dass dieser Fall eine secundäre Streptococcendiphtherie war, $1 \mathrm{~m}$ so $\mathrm{mehr}$, als das klinische Bild fill die septische Forml charakteristisch war, und es sich im Verlaufe eines Scharlachs entwickelt hat. Der Fall ist der folgende:

M. L., 3 Jahre altes, schlecht genährtes Mädchen, war, abgesehen von häıfgem Ohrenfluss, bis jetzt gesund. Am 19. vorigen Monats ist sie an Scarlatina mit mässigem Fieber und Rachenerscheinungen erkrankt. Die Eruption hat sich rasch entwickelt. Am folgenden Tage erreichte sie ihren Höhepunkt. An den Tonsillen mässige Folliculitis. Am dritten Tage der Erkrankung sind die Rachenerscheinungen verschwunden, der Ausschlag in Riickbildung begriffen. Patientin fieberlos. Am 22. zeigte sich an beiden Tonsillen ein dïnner, grauer, durchschimmernder Belag mit mïssiger Schwellıng der Cervicaldriïsen. Am 23. sind stürmische Erscheinungen in den Vordergrund getreten. Das bisher gute Allgemeinbefinden verschlimmerte sich, die Cervicaldrüsen waren beiderseitig stark geschwellt. Ein stark ubelriechender Gernch aus dem Munde. Ich sah Patientin am 23. in der Mittagsstunde. Die stark abgemagerte Patientin liegt matt im Bette. Athmet mit halbgeoffnetem Munde. Stimme beim Weinen nïselnd. Die Ungebung der Nasenöffnung excoriirt und entziindet. Am Septum eine düıne, grauweissliche Membran. Ans der Nase fliesst eine serösschleimige Fliussigkeit; Lippen entziindet, auf ihrer Schleimhaut sind nehrere excoriirte Stellen sichtbar, meistentheils mit oraulicher Menıbran bedeckt. Rachengebilde sehr mässig geschwellt und kaum entzündet. Tonsillen, hintere Rachenwand, Uvula odematös infiltrirt, ihre Oberfläche ist mit einer schmutzigen, granen, dïnnen Membran bedeckt (die sich in die Tiefe der Schleimhant hineinzieht). Aus dem Munde iibeler Geruch. Beiderseits des Halses, hauptsächlich aber links, sind bis wallnussgrosse Drüsenschwellungen sichtbar, die mit normaler Haut bedeckt sind. Am Körper sind dem abgelaufenen Scharlachexanthem entsprechende Pigmentflecken zll sehen. Die Ernährung geht ziemlich gut von statten.

Die eben geschilderten Symptome zeigen das Bild der malignen Scharlachdiphtherie, deren Prognose eine sehr traurige ist. Eine sehr wichtige Frage war die, ob wir es hier mit einer Scharlachdiphtherie, oder - in Anbetracht dessen, dass die Diphtherie erst später während der Zurriickbildung des Exanthems sich entwickelt hatte - mit einer zur gemcinen Diphtherie gehörenden Diphtherie zu thun hatten, resp. ob wir mit einer Serumbehandlung einen Erfolg erzielen konnten? Die Frage konnte nur auf bacteriologischer Basis gelöst werden, dies nahm aber wenigstens 24 Stunden in Anspruch. Jedoch in diesem schweren Falle 24 Stunden zll warten - konnte verhänonissvoll sein! Das klinische Bild sprach fïr eine Scharlachdiphtherie, fïr eine secundäre Diphtherie im strengsten Sinne des Wortes; sie stellte eine secundäre Infection während der Rückbildung des Exanthems dir. Das geeignete Moment dafür bildete die Angina follicularis scarlatinosa als primäre Erkrankung, trotzdem diese am dritten Krankheitstage vor dem Erscheinen der malignen Infection sich besserte.

In Anbetracht der ernsten Symptome, die eine Genesung kaum erloffen liessen, entschlossen wir uns zur Serımbehandlung. Unter solchen Umständen gaben wir die erste Injection von dem Behring'schen Serum No. III. In den nächsten 24 Stunden zeigte sich nichts Ermunterndes, inl Gegentheil, Sopor und Mattigkeit nahmen zu. Bloss eine Abnahme des Foetors ex ore konnten wir constatiren und dass die von Belag freigebliebenen Stellen des Rachens intensiv roth sind. Die Drusenschwellıngen sind unverändert. Am selben Tage Abends hörte das Uebelriechen des Mundes beinahe vollkommen auf, der Sopor liess nach, das Allgemeinbefinden besserte sich. Die zweifellosen Zeichen einer allgemeinen Besserung hatten sich im Lalfe der Nacht in prägnanter Weise geäussert, und bis Morgens trafen wir das Kind in der Reconvalescenz. Auch die lokalen Erscheinungen zeigten dementsprechend eine erfreuliche Besserıng. Der membranöse Belag exfoliirte sich aus den Geweben, die tubrigen 
Theile des Rachens zeigten eine nurmale Rüthe. Die Drüsensclıwellıng nahm rechts wesentlich, links mässig ab.

Auf diese auffallende Besscrung folgte vom 25. Morgens ab einc rapide Genesung. Am 28, reinigten sich gänzlich Rachcn, Nase, Lippcn. Drüsenschwellumg war bloss links vorhandell, die auch constant geblieben ist, später vereiterte sie und wurde geöffnet.

Die kleine Patientin fühlt sich heute vollkommen gut, von cinen Nierenleiden ist keine Spur vorhanden.

Die Behandlung bestand bis zum 24. in Halsausspülungen mit Aqua Calcis und Spirituosen, später mit 3\% wurden die Rachengebilde mit einer $5 \%$ igen Ferrum sesquichloratum-GlycerinLösung fünfmal gepinselt.

Die am 23. und 28. vorgenonimenc bacteriologische Untersuchung zeigte bloss Streptococcen und Staphylococcen. Diphtheriebacillen fand ich - trotz genauester Untersuchung - nicht. Das oben geschilderte Bild des Rachens, der Zusammenhang mit Scharlach, die später eingctrctcne Abscedirung sprachen alle fïr eine Streptococcendiphtheric.

Zweifellos ist die Heilung infolge der Serumbchandlung cingetreten. Die in 24 resp. 36 Stunden eingetretene rapide und auffallcnde Besserung, wie wir sic bei der Serumbehandlung beobachten können, beweist dies zur Genuge.

Die erste Frage, die uns auf den Lippen schwebt, ist die, wie wir diese Wirkung des Serums mit der Speciftit des Serums in Finklang bringen können? Diese Frage zu bcantworten, ist eine schwcre Aufgabe. Es ist schwer zu erklären, dass das antidiphtheritische Scrum auch andere Krankhciten heilen kann. Wir diurfen abcr nicht vergessen, an auf dem VIII. hygienischen Congress von Roux und Metschnikoff gchaltenen Vortrag über dic Erklärung der gemischten Immunität zu erinnern. Es ist nämlich bekannt, dass das gegen Rabies geimpftc Thier auch gegen acute Septicämie und Schlangengift immun ist und dass die Immunität gegen Schlangengift auch gegen Abrin oder Tetanus besteht. Nun haben wir hicr ein und dassclbe Serum, welches gegen vcrschiedene Krankheiten schutzt. Zur Erklärung dieser Sache dient die Metschnik off'sche "stimulirende" Theorie, der zufolge das injicirtc Antitoxin die weissen Blutkörperchen vermehrt und diese zur Phagocytose stimulirt. Demzufolge ist es kein chemischer Process, sondern dic gcsteigerte biologische Function der lebenden Zellen die die Immunisation bewirkt.

Die zweite Frage ist, ob das Serum eine durch Streptococcen verursachte, mit heftigen Erscheinungen verlaufende Diphtherie auch in allen Fällen so günstig zu beeinflussen imstande ist. Weitere Beobachtungen sind nöthig zur Lósung dieser Fragc, und wir wollen hoffen, dass wir bei der weit verbreiteten Serumbehandlung auch in dieser Beziehung eine Aufklärung bekommen. Aus den bis jetzt bekannt gcwordenen Publicationen und Beobachtungen geht zweifellos hervor, dass die Serumtherapie die Drüsenschwellungen und den Foetor ex ore meistens günstig beeinflusst - Erscheinungen, die speciell durch Streptococcen bedingt sind. 